\title{
INFORMES
}

\section{INFORME SOBRE IA "CONFERENCIA DE LA ENCUESTA MUNDIAL DE FECUNDIDAD" CELEBRADA EN LONDRES DEL 7 AL 11 DE JULIO DE 1980}

A comienzos de la década de los setenta el Instituto Internacional de Estadística en colaboración con las Naciones Unidas y la Unión Internacional para Estudios de Población lanzó un proyecto para la realización de encuestas de fecundidad en el mayor número posible de países. Estas encuestas debían ser representativas a nivel nacional y comparables a nivel internacional. Para promover y financiar este programa se contó con la ayuda del "Fondo de las Naciones Unidas para Actividades de Población" (UNFPA) y la Agencia para el Desarrollo Internacional, de los Estados Unidos (A.I.D.) además, de la contrapartida presupuestaria que cada país participante debía aportar para el levantamiento de su propia encuesta.

La encuesta se llevó a cabo en 65 países habiendo sido todas asesoradas por la aficina sede de la Encuesta Mundial que funciona en Londres misma, que organizó la conferencia para la cual solicité asistir con apoyo económico de CONACYT.

La solicitud presentada para obtener este apoyo se fundaba en mi estrecha vinculación con la Encuesta Mexicana de Fecundidad desde sus inicios y principalmente, en ser responsable en la actualidad de un proyecto de investigación con datos de esta misma encuesta en cuyo financiamiento participa la Oficina de la Encuesta Mundial de Londres.

Con la presente conferencia culminaba el proceso de levantamiento, y también en parte, el de análisis, de las encuestas de fecundidad. Este proceso representa una experiencia única hasta la fecha en cuanto a obtener información comparable sobre un tema a nivel mundial. Dadas estas características la importancia de esta encuesta se ubica tanto a nivel estadístico general como a nivel especializado en lo que respecta a análisis de la fecundidad y de sus interrelaciones con nupcialidad y mortalidad especialmente. 
Los trabajos presentados, en un número de 36 , se centraron alrededor de tres aspectos: 1) Aportes, críticas y perspectivas de la encuesta (Sesiones Plenarias); 2) Aspectos metedológicos relacionados con el tratamiento de la información contenida en los cuestionarios de la encuesta (Sesiones Metodológicas); 3) Estudios de casos (principales hallazgos en diferentes países).

Cada sesión estuvo a cargo de un organizador-ponente de mucha experiencia en el tema de la sesión y de dos comentaristas especialistas en la misma materia.

Por su parte, la participación de los asistentes (alrededor de 600 personas), ligadas en su mayoría al análisis de las encuestas en los diferentes países, enriqueció la visión que uno pudiera tener con respecto a las potencialidades de análisis así como de los límites de estas encuestas. También puede considerarse como un aporte importante la discusión que se đesarrolló en torno a diferentes enfoques metodológicos que pueden ser utilizados para avanzar en lo que respecta a la descripción de los niveles y tendencias de la fecundidad y de los aspectos más íntimamente relacionados con la determinación de éstos (mortalidad intrauterina, nupcialidad).

Los resultados obtenidos con un programa de encuestas de esta envergadura se pueden evaluar desde distintos ángulos pero en términos generales, sin entrar a profundizar, se pueden señalar los siguientes:

a) La encuesta logró su objetivo de hacer participar a un número importante de países desarrollados y en vías de desarrollo con el fin de lograr un diagnóstico de los niveles y tendencias de la fecundidad. Con la encuesta se confirma la incorporación de los países menos desarrollados al movimiento de descenso de la fecundidad.

b) Es factible levantar una encuesta que permita recabar información comparable para muchos países. El esfuerzo metodológico desarrollado puede ser aprovechado en el estudio de otros fenómenos demográficos o de índole semejante.

c) El levantamiento y análisis de la encuesta ha generado un importante banco de datos y también la preparación de un importante contingente de analistas en numerosos países.

d) La encuesta ha aportado una profundización en lo que respecta a las relaciones entre la fecundidad y sus determinantes más inmediatos, véase "variables intermedias" (edad al unirse, duración de la unión, lactancia, mortalidad infrauterina, etc.) pero no llevó a un esclarecimiento de la forma en que operan los condicionantes socioeconómicos culturales sobre los niveles y tendencias de la misma. Esto último fue una carencia del propio "cuestionario base" de la encuesta que respondía más a un objetivo descriptivo que a uno de tipo explicativo de los niveles y tendencias de la fecundidad. Esto no significa que no se hayan incluido preguntas sobre características socioeconómicas, esto se hizo para las mujeres entrevistadas habiéndose concluido que la característica que más influye sobre el comportamiento reproductivo es el nivel educacional que estas mujeres poseen.

El provecho que puede brindar a un investigador la asistencia a una conferencia de esta naturaleza difícilmente puede medirse en forma tangible ya que se traduce más bien, en un proceso de reflexión sobre la in- 
vestigación que esté llevando a cabo a la luz de las nuevas ideas que se plantean en las ponencias o, que surgen de las discusiones a las cuales se asiste. En mi caso, por el hecho de estar en este momento participando en un proyecto de investigación basado en el análisis de los datos de la Encuesta Mundial de México, la incorporación de los avances que se consideren pertinentes podrá hacerse con relativa facilidad y oportunidad. En este sentido, se puede decir que la conferencia se llevó a cabo en un momento muy oportuno para mi trabajo personal vistos los aportes que pueden ser aprovechados y la discusión que pude realizar sobre mi proyecto en particular, con algunos otros investigadiores presentes.

Además, se aprovechó la conferencia para tratar algunos otros aspectos relacionados con mi proyecto de investigación, tales como: 1) Informe sobre el estado de avance del proyecto ("Niveles de Fecundidad y Patrones de Nupcialidad en México" del cual soy investigador responsable en el COLMEX) al señor German Rodríguez, del Staff del World Fertility Survey; 2) Agilización de ciertos trámites administrativos relacionados con el convenio de apoyo financiero entre el COLMEX y el W.F.S. al proyecto antes mencionado; 3 ) Obtención de las publicaciones recientemente aparecidas en el marco del W.F.S. que son de gran utilidad para mi propia investigación como para la de otros investigadores del COLMEX.

Julieta Quilodrán 